\title{
Efficient chemical stabilization of tannery wastewater pollutants in a single step process: Geopolymerization
}

\author{
Giacomo Boldrini $i^{1 *}$ D, Caterina Sgarlata ${ }^{2}$, Isabella Lancellotti ${ }^{2}$, Luisa Barbieri ${ }^{2}$, Marco Giorgetti ${ }^{3}$, Michela Ciabocco ${ }^{4}$,
} Silvia Zamponi ${ }^{1}$, Mario Berrettoni ${ }^{1}$ and Cristina Leonelli ${ }^{2}$

\begin{abstract}
The treatment of tannery wastewaters is a complex task due to the complexity of the waste: a mixture of several pollutants, both anionic and cationic as well as organic macromolecules which are very hard to treat for disposal all together. Geopolymers are a class of inorganic binders obtained by alkali activation of aluminosilicate powders at room temperature. Such activation process leads to a cement like matrix that drastically decreases mobility of several components via entrapment. This process taking place in the matrix can be hypothesized to be the in-situ formation of zeolite structures. In this work we use a metakaolin based geopolymer to tackle the problem directly in an actual industrial environment. To obtain a geopolymer, the metakaolin was mixed with $10 \mathrm{wt} \%$ of wastewater added with sodium hydroxide and sodium silicate as activating solutions. This process allowed a rapid consolidation at room temperature, the average compressive strength was between 14 and $43 \mathrm{MPa}$. Leaching tests performed at different aging times confirm a high immobilization efficiency close to $100 \%$. In particular, only the 0.008 and $2.31 \%$ of Chromium and Chlorides respectively are released in the leaching test after 7 months of aging.
\end{abstract}

Keywords: Tannery, Alkali activation, Leaching test, Waste stabilization/solidification, Chromium-containing liquor

\section{Introduction}

Hazardous waste management involves the reduction of the amount of hazardous substances produced, or treatment of hazardous wastes, to reduce their toxicity, preferably using green technologies. In this context, the tanning industry has a strong impact. This industry has been consistently present in the economy of many countries such as China, Brazil, Russia, and Italy throughout the centuries [1]. The second half of the twentieth century saw a massive increase in the production and usage of leather footwear. This industrial field is, therefore, a key process for the economic growth of said countries.

Even though in the past 15 years the Chinese leather industry has grown at a fast pace, Italy still retains its

\footnotetext{
*Correspondence: giacomo.boldrini@unicam.it

'University of Camerino, School of Science and Technology, 62032 Camerino, Italy

Full list of author information is available at the end of the article
}

spot in leadership, despite the population disparity, the environmental concern and consequently stricter regulation. This means that the Italian tanning industry is a massive player in the worldwide bovine leather production, which was registered at almost US $\$ 20$ billion in 2014 worldwide, contributing more than US $\$ 4$ billion dollars [1]. Looking at the statistics reported by Food and Agriculture Organization of the United Nations, the higher values of bovine leather market belong to Europe with US\$7706 million in 2014, of which more than half belongs to Italy ( $54 \%$ of the total) with US\$4214 million in 2014 [2].

Unfortunately, this positive data has a drawback: the tanning industries produce a large amount of liquid waste (for the total process is estimated at $100 \mathrm{~L}$ for $\mathrm{m}^{2}$ of leather [3]) that is difficult to treat before disposal with high toxic potential due to chromium, soluble anions and surfactant content. This is one of the main

(c) The Author(s). 2021 Open Access This article is licensed under a Creative Commons Attribution 4.0 International License, which permits use, sharing, adaptation, distribution and reproduction in any medium or format, as long as you give appropriate credit to the original author(s) and the source, provide a link to the Creative Commons licence, and indicate if changes were made. The images or other third party material in this article are included in the article's Creative Commons licence, unless indicated otherwise in a credit line to the material. If material is not included in the article's Creative Commons licence and your intended use is not permitted by statutory regulation or exceeds the permitted use, you will need to obtain permission directly from the copyright holder. To view a copy of this licence, visit http://creativecommons.org/licenses/by/4.0/. 
causes of water pollution in many recently industrialized countries $[4,5]$. Tannery liquid wastes are composed of variable mixtures of anionic and cationic pollutants, as well as organic macromolecules of surfactants which are very hard to treat for disposal all together [6]. In Italy, tannery waste liquors are treated mainly by districts and centralized consortia with recognized benefits for those industries that are part of a consortium. Specifically, the complexity of tannery wastewater, which corresponds to the highest pollutants among all industrial wastes and cause stratification, has been the subject of many studies throughout the years [7-10]. The entire leather processing, in fact, involves a huge amount of water usage and chemical agents (such as $\mathrm{NaCl}$, vegetable tannins, chromium salts, sulfides and sulphates) in most of the main stages [11]. Tannery effluents are of large-scale environmental concern because they contaminate water bodies into which they are released. The organic pollutants derive from the organic degradation products of the raw materials (epidermis, fats, proteins) or are residues of the organic products used in the process, while the inorganic ones come from the chemical additives used in the various phases of the production cycle. To fall within the limits established by current regulation, these wastewaters with a high pollution load must be treated adequately and the product is usually a sludge with a high content of pollutants, especially chromium. This is valid for heavy metals among which chromium is one of the most common, taking into account that the basic chromium sulphate salt, $\left[\mathrm{Cr}_{2}\left(\mathrm{H}_{2} \mathrm{O}\right)_{6}(\mathrm{OH})_{4}\right] \quad \mathrm{SO}_{4}$ (CAS\#39380-78-4), is the tanning agent most employed by the industry. The main concern in wastewater treatment is to avoid the oxidation of Cr (III) to Cr (VI) due to the high toxicity of the latter.

There are a few other studies [12-15] that inertize a tannery complex matrix of pollutants via stabilization/ solidification $(\mathrm{S} / \mathrm{S})$ techniques, most of them however, treat/stabilize the tannery sludges which have been obtained at the end of wastewater treatments. In particular, Pantazopoulou and Zouboulis reported the best results with dry sludges added with ladle furnace slag, organoclay and water [13]; Montanes et al. also use dry sludges with Portland cement and water with a 9 to 1 ratio (waste to cement) [14]. Haque et al. are one of the very few research groups that used wastewater without filter pressing to make a sludge, however it was still pretreated via filtration through a filter paper (decreasing pore size from 30 to $20 \mu \mathrm{m}$ ) to obtain wastewater suitable for the proposed process (total $\mathrm{Cr}$ content of 7.5 $\mathrm{mg} \mathrm{L}^{-1}$ ) [15].

The uniqueness of our work lies in the absence of wastewater (total $\mathrm{Cr}$ content of $4100 \mathrm{mg} \mathrm{L}^{-1}$ ) pretreatment. To keep the complex composition of pollutants intact, we used a real matrix instead of resorting to synthetic waters, for this reason the wastewaters we used were taken directly from the tanning drum at the end of the tanning process bypassing all the sub sequential treatment steps. Our choice was dictated by the fact that the literature is poor of works that explore the idea of an overall treatment of a real liquid waste containing several pollutants in addition to chromium [16].

We have considered a low environmental impact technology to treat this kind of waste, i.e., the use of "geopolymers", a class of inorganic binders obtained by alkali activation of aluminosilicate powders at room temperature. Geopolymers have already been used in literature to render inert $\mathrm{Cr}$-bearing solid or liquid waste [17-21]. The "geopolymerization" process leads to a cement-like matrix that stabilizes after solidification of several chemical components, including chromium, chlorides, sulphates.

Other works have removed $\mathrm{Cr}$ ions from waters using adsorbent materials, but they have not clearly indicated how to treat the final Cr-rich solids [22-24].

The advantage of the geopolymer approach, a low cost and low impact process, is the feasibility to reduce the environmental impact of wastewater management, making them either easier to dispose of or inert all together. The innovation and originality of our method rises from the use of a single geopolymer formulation not specific to a single pollutant, but suitable for several cations and anions, as well as organic macromolecules, all present in a complex liquid waste form. Adopting such S/S approach we use binders and additives to reduce the mobility and toxicity of the pollutants contained in wastes and we generate a final product suitable for reuse or for safe disposal. In comparison to our previous studies [17] the increased complexity of the current work is demonstrated as we utilized the as-received wastewater derived from the tannery process containing larger amounts of anions and macromolecules of surfactants.

We demonstrated the effectiveness of the proposed procedure by checking the released amounts of cations and anions during the leaching test according to the European norm UNI EN 12457-2-2004 "Characterization of waste Leaching Compliance test for leaching of granular waste materials and sludges". In practice, the chemical stabilization method that we are proposing could be easily implemented in the tannery plant, cutting down costs without modification of the leather manufacturing cycle [25] and unnecessary waste transportation.

\section{Materials and methods}

Tannery wastewater: origin and characterization

The liquid waste used in this study is not a synthetic waste [17] but comes directly from the main tanning step that produces several problematic pollutants, such 
as large amounts of chromium with concentration much higher than $2500 \mathrm{mg} \mathrm{L}^{-1}$, high sulphates $\left(15,873 \mathrm{mg} \mathrm{L}^{-1}\right)$ and chlorides $\left(17,300 \mathrm{mg} \mathrm{L}^{-1}\right)$ load mostly due to the use of tanning salts. Thus, we focused our attention on a real tannery waste coming directly from an industrial site, one of the historical Italian tanneries: CTC Conceria del Chienti, Tolentino Italy. Table 1 reports the concentration of the most relevant pollutants, cationic, anionic forms and surfactants of the untreated tannery waste liquor. The error, which does not refer to the standard deviation but to the expanded uncertainty that takes into account the whole analytical method, for the metals analyzed it is on average $30 \%$ whereas for the anions it is around $15 \%$. No pre-treatment [26] was operated on the as-received wastewater except for concentration (see later discussion).

The values reported in Table 1 are in line with those of several Italian tanneries, as stated in the "Cost of tannery waste treatment" report commissioned by United Nations Industrial Development Organization in 2011 [6]. The very high amount of the marked pollutants (indicated by a symbol) in Table 1 makes the wastewater potentially hazardous for the health and the ecosystem, and there is concern that the surfactants may facilitate the diffusion of the other contaminants [27].

\section{Metakaolin characterization}

The metakaolin (MK) (Argical ${ }^{\mathrm{m}}$ M1000) used in the preparation of all geopolymer formulations as the

Table 1 Results of the analysis of tannery wastewater as received. (Except $\mathrm{pH}$, all in $\mathrm{mg} \mathrm{L}^{-\mathbf{1}}$ )

\begin{tabular}{ll}
\hline & Tannery wastewater $\left(\mathbf{m g ~ L}^{\mathbf{- 1}}\right)$ \\
\hline $\mathrm{pH}$ & 7.1 \\
$\mathrm{SO}_{4}{ }^{2-}$ & $15873^{\mathrm{a}}$ \\
$\mathrm{Cl}^{-}$ & $17300^{\mathrm{a}}$ \\
Total surfactants & $130^{\mathrm{a}}$ \\
Non-ionic surfactants & 85 \\
Anionic surfactants & 45 \\
Aluminum & 78 \\
Arsenic & $<$ quantification limit \\
Barium & 0.85 \\
Chromium total & $4100^{\mathrm{a}}$ \\
Copper & 1.6 \\
Iron & 22.6 \\
Manganese & 7.4 \\
Nickel & 1.25 \\
Lead & 0.55 \\
Tin & $<$ quantification limit \\
Zinc & 3.4 \\
\hline
\end{tabular}

Indicates presence of substance of concern principal source of aluminosilicate, was produced by Imerys, France, and supplied by Bal-Co SpA, Italy. The MK was ground and sieved below $75 \mu \mathrm{m}$. The oxides composition (Table 2) of the metakaolin, determined by the producer by $\mathrm{X}$-ray fluorescence $(\mathrm{XRF})$, gave a value of $\mathrm{Si} / \mathrm{Al}=1.3$ in terms of mass ratio.

The X-ray powder diffraction characterization showed the broad band typical of amorphous metakaolin between 20 and $25^{\circ} 2 \theta$ angle, together with minor residual crystalline phases identified as: muscovite $\mathrm{KAl}_{2}\left(\mathrm{Si}_{3} \mathrm{~A}\right.$ 1) $\mathrm{O}_{10}(\mathrm{OH}, \mathrm{F})_{2}$; quartz $\mathrm{SiO}_{2}$; and anatase $\mathrm{TiO}_{2}[17,28]$.

\section{Geopolymers formulation}

Two different solutions containing waste from the tanning of bovine skin have been investigated: the first type of wastewater is the liquor that comes out of the tanning drum, whilst the second type is the first one concentrated 2:1 (v/v) through evaporation. These two wastes are indicated: TWN, wastewater as received, and TWC, wastewater after concentration.

The formulations are tailored using $\mathrm{MK}$ as a matrix for geopolymers. The choice of MK is due to the complexity of the waste liquors [19]. Therefore, a wellstudied aluminosilicate precursor with known chemical behaviour as MK has been selected to better focus the attention on the role of liquors only. The following formulations were used to prepare MK-based (Fig. 1) geopolymers:

1. Mixing of $14 \mathrm{wt} \%$ of sodium hydroxide pellets (Reagent Grade, Sigma -Aldrich) and $66 \mathrm{wt} \%$ of sodium silicate solution with ratio $\mathrm{SiO}_{2} / \mathrm{Na}_{2} \mathrm{O}=3$ (43 wt\% of sodium silicate in water with density of $1.5 \mathrm{~g} \mathrm{~mL}^{-1}$, produced by Ingessil, Italy) in a beaker containing $20 \mathrm{wt} \%$ of liquid waste (calculated on the MK weight) to obtain a homogeneous solution;

2. Addition of MK to form a homogeneous slurry;

3. Intensive/thorough stirring until a homogeneous and fluid paste is formed; the paste is poured into plastic molds;

Table 2 Results of the chemical analysis via XRF Analysis of Metakaolin Argical TM M1000 as received from the producer

\begin{tabular}{ll}
\hline Metakaolin & \% by weight \\
\hline $\mathrm{SiO}_{2}$ & 58.9 \\
$\mathrm{Al}_{2} \mathrm{O}_{3}$ & 34.7 \\
$\mathrm{Fe}_{2} \mathrm{O}_{3}$ & 1.4 \\
$\mathrm{CaO}$ & 0.1 \\
$\mathrm{MgO}$ & 0.1 \\
$\mathrm{Na}_{2} \mathrm{O}$ & 0.1 \\
$\mathrm{~K}_{2} \mathrm{O}$ & 0.7 \\
$\mathrm{TiO}_{2}$ & 1.3 \\
\hline
\end{tabular}




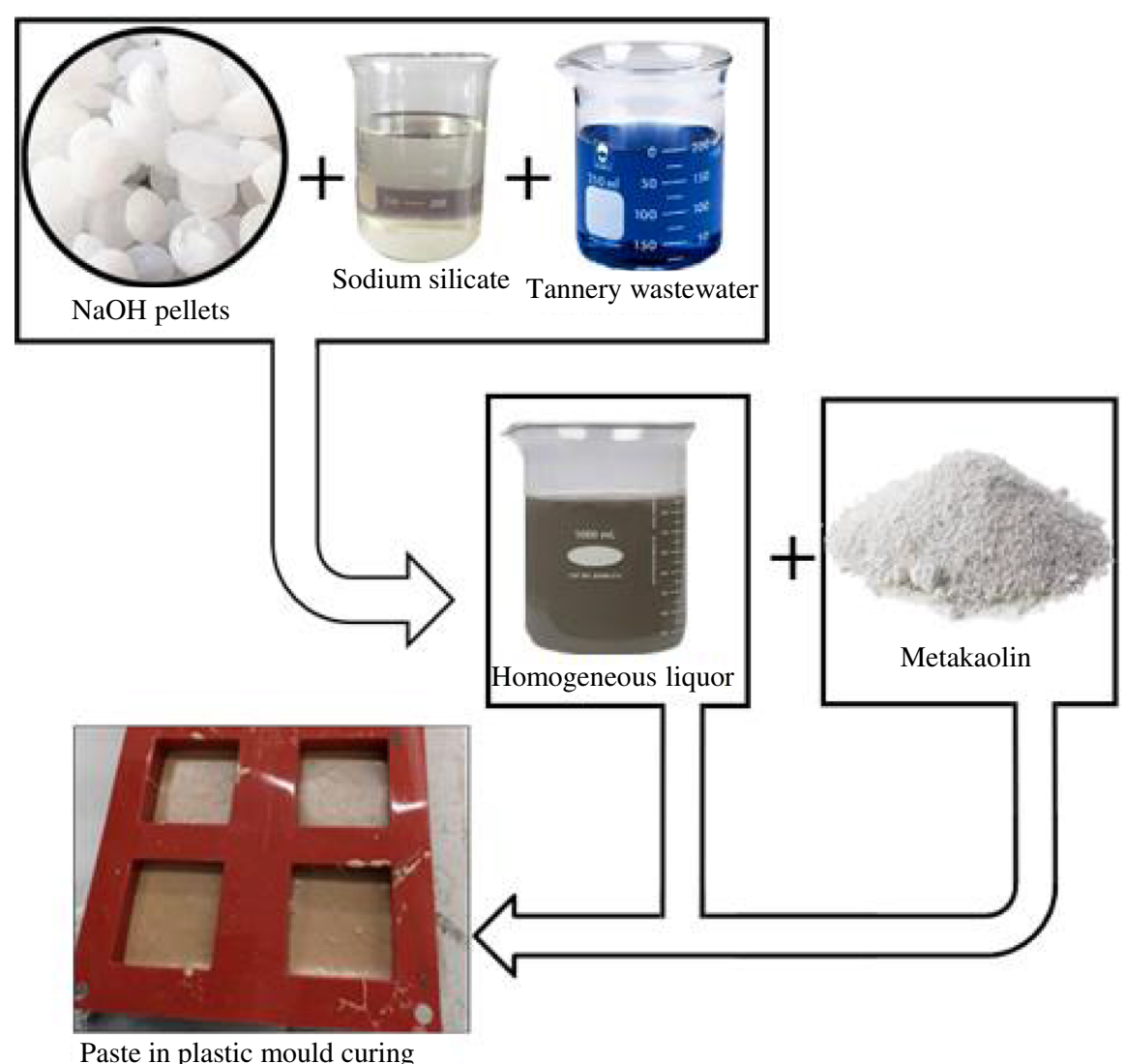

Fig. 1 Schematic representation of the Geopolymer preparation steps as described in the text

4. Setting stage maintaining the cast at room temperature in a plastic bag for $24 \mathrm{~h}$, then in open air;

5. Curing stage at room temperature and in open air for $28 \mathrm{~d}$.

The wet paste, taking into account the MK composition reported in Table 2, had the following molar ratios: $\mathrm{SiO}_{2} / \mathrm{Al}_{2} \mathrm{O}_{3}=2.45, \mathrm{Na}_{2} \mathrm{O} / \mathrm{SiO}_{2}=0.49, \mathrm{Na}_{2} \mathrm{O} / \mathrm{Al}_{2} \mathrm{O}_{3}=1.2$, and $\mathrm{H}_{2} \mathrm{O} / \mathrm{Na}_{2} \mathrm{O}=1.85$.

\section{Geopolymer chemical stability and leaching tests}

We tested the chemical and structural integrity of the final consolidated product, after at least $7 \mathrm{~d}$ from preparation, by submerging a piece of geopolymer in distilled water, solid to water ratio $1: 100$, for $24 \mathrm{~h}$ at room temperature. The test allowed evaluation of the material's resistance to dissolution and consequently the efficiency of the geopolymerization process as adopted also in [28].

We also performed a leaching test, according to UNI EN 12457-2-2004, "Characterization of WasteLeaching-Compliance test for leaching of granular waste materials and sludges" at 4, 20, and 28 wk. After the synthesis: the dry sample was weighed, powdered and put in bi-distilled water with a ratio $1 / 10$. The mixture was left to stir for $24 \mathrm{~h}$ at room temperature, and the eluate was characterized with Inductively Coupled Plasma - Optical Emission Spectroscopy (ICP/OES); the limits of quantification are reported in Table S1.

To assess the elementary composition of the geopolymers, we performed the necessary analysis on the liquid resulting from mineralization.

\section{Mechanical characterization}

Ultimate compressive strength of the consolidated geopolymers after $28 \mathrm{~d}$ of ageing was determined using an Instron 5567 Universal Testing Machine with $30 \mathrm{kN}$ load limit and displacement of $3 \mathrm{~mm} \mathrm{~min}^{-1}$ according to the standard UNI EN 826. Specimens were cast in cubic molds of $25 \times 25 \times 25 \mathrm{~mm}$ in size (Fig. 1), with two perfectly flat and parallel faces to avoid the requirement for capping. Three different specimens were made following the same formulation: one containing tannery wastewater as received (MTWN), one with tannery wastewater concentrated 2:1 via evaporation (MTWC) and a reference geopolymer using deionized water instead of tannery wastewater (Pure MK). The values of compressive 
strength are given as range of mean value, accompanied by the maximum deviation from the mean value of 3 measurements, because the small size of the specimen was particularly affected by manual mixing and uneven pouring.

\section{Efficiency of waste inertization}

The stability of the geopolymer matrix and its capability to immobilize $\mathrm{Cr}$ (III) ions was assessed according to specific European regulations, reported above. Instruments and methods used are outlined as follows:

i the measurement of soluble metal ions was done with an ICP/OES, AGILENT ICP-OES 5100 VDV, according to UNI EN 13656:2004, UNI EN 13657:2004, UNI EN 13657:2004, UNI EN ISO 11885:2009.

ii The anions were measured by ionic chromatography, METROHM ECO IC following the UNI EN 12457-2:2004, BS EN 27888:1983 APAT CNR IRSA 4020 MAN 29:2003; APAT CNR IRSA 5030 MAN 29:2003.

iii Anionic surfactants, non-ionic surfactants, cationic surfactants were analyzed using $\mathrm{HACH}$ analyzing kit (LCK 331, LCK332, LCK 333).

The leaching test was performed according to UNI EN 12457-2-2004 at different ageing times (28 d, 5 and 7 months). The choice of evaluating the chemical stability after 5 and 7 months was suggested by the need of checking materials durability.

\section{Results and discussion}

The consolidated materials were first subjected to visual inspection. It was confirmed that the liquid form of the waste allowed a homogeneous mixing at macroscopic level: the color appeared slightly greyish and uniform, no stratification was observed, nor surface cracking or chipping. The $24 \mathrm{~h}$ curing period in the closed plastic bag helps geopolymerization to occur properly, hence the water evaporation during the next days does not provoke cracking or crazing and the sample resulted macroscopically consolidated. Nevertheless, at the atomic scale, geopolymerization reaction continues as observed in literature $[17,28]$ prompting the need to conduct a leaching test after $28 \mathrm{~d}, 5$ and 7 months. The Scanning Electron Microscopy (SEM) observation coupled with Energy Dispersive X-ray (EDS) analysis shows the homogeneous microstructure where an amount of $0.5 \mathrm{wt} \%$ of Cr was detected (Fig. 2a where Back-Scattered Electrons (BSE) image is reported). The morphology of the geopolymer gel [20] is clearly visible, and the homogeneity in the grey color of the BSE image indicates the uniform distribution of the heavy metals. Only small air bubbles have been entrapped within the paste during the hardening stage, as confirmed by the variability of the compressive strength values. At higher magnification (Fig. 2b), areas with concentrated presence of $\mathrm{Cr}$ (the average range obtained with several analyses in different areas of the sample is $0.7-0.9 \mathrm{wt} \%$ as detected by EDS) is observed corresponding to needle-shaped crystal. The cracks visible in both SEM images are due to the fracturing operations adopted for the sample preparation.

The compactness of the consolidated bulk materials is responsible for the good mechanical resistance recorded for these materials in the compression tests: the values of compressive strength are $13.8 \pm 1.5 \mathrm{MPa}$ for the MTWN, $43.1 \pm 2.0 \mathrm{MPa}$ for the MTWC and $30.3 \pm 5.0$ MPa for the pure MK.

The geopolymers of formulations MTWN and MTWC showed extremely good durability in water and average (30 MPa) to high (70 MPa) compressive strength [29], especially when concentrated $\mathrm{Cr}$-waste was used. In this case, a strength of $45 \mathrm{MPa}$ could be reached when

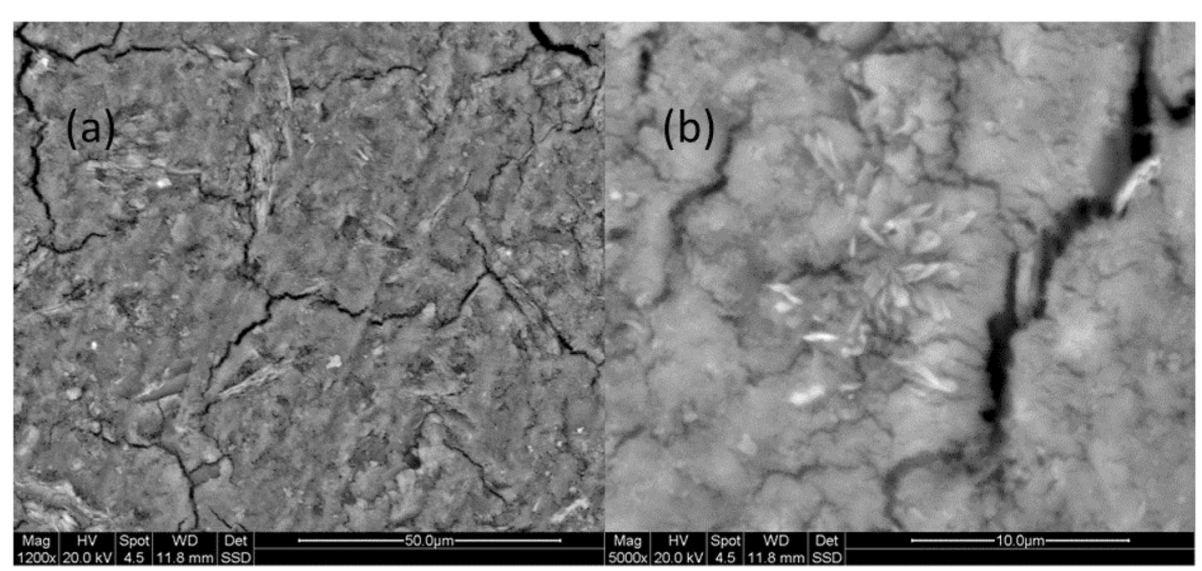

Fig. 2 SEM results reporting the BSE image of a freshly fractured geopolymer (MTWC) surface at different magnifications: a 1200x and b 5000x 
defect-free specimens were prepared. As indicated above, the presence of air bubbles entrapped in the paste generated local defects and originated failure cracking, as in the case of sample MTWN. Even though the test precision is less than $1 \%$, we preferred to provide the maximum deviation from the mean value to show the variability of these results. It should be noted that the mechanical performance of the geopolymers was not our focus, for this reason it was decided not to adopt an additional de-bubbling procedure. Apart from entrapped air bubbles reducing the compressive strength, there were no other reasons for expecting strong variation of compressive strength values with time. This hypothesis was confirmed when checking good geopolymerization, via SEM observations and integrity tests as well as leaching.

On the contrary, the main goal of the alkaline activation of $\mathrm{MK}$ containing the liquid $\mathrm{Cr}$-bearing waste was the efficient chemical stabilization and inertization [28]. The potential hazardousness of the tannery wastewater is related to the leachability of $\mathrm{Cr}$ (III) which could oxidize to $\mathrm{Cr}$ (VI) when exposed to air. With the aim to evaluate the actual capability of the MK-based geopolymer to retain anions and cations, as well as surfactants, we first measured the content of pollutants inside the formulated samples by dissolving and digesting the solid MTWN and MTWC in acid after 28 days of curing. Following the procedure UNI EN 13656:2004 ("Characterization of waste - Microwave assisted digestion with hydrofluoric (HF), nitric $\left(\mathrm{HNO}_{3}\right)$, and hydrochloric $(\mathrm{HCl})$ acid mixture for subsequent determination of elements") for the element determination, it was not possible to actually detect the presence of $\mathrm{Cl}^{-}$in the waste, since hydrochloric acid was used; for this reason, the numbers shown in Figs. 3 and 4 are an estimation based on the stoichiometric parameters synthesis of MK geopolymer. All the other pollutants were quantitatively determined, specifically the content of $\mathrm{SO}_{4}{ }^{2-}$ (Figs. 3 and 4, reported below, and Tables S2 and S3 in the supplementary materials). Once we were sure that our alkali activated materials contained the pollutants, we started to run the leaching tests. The sample was pulverized right before testing. We focused our attention on $\mathrm{Cr}$ and other cations, as well as anions and, eventually, macromolecules of surfactants.

Figures 3 and 4 show the leaching potential of the main pollutants after geopolymerization at different aging times. The first column for each element corresponds to the amount of substance present in the geopolymer matrix (collected on digested specimen according to UNI EN 13656:2004), the second, third and fourth columns show respectively the results of the leaching tests performed after $28 \mathrm{~d}, 5$ months and 7 months according to UNI EN 12457-2-2004. In the supplementary materials we reported all the other pollutants tested. The horizontal bars of Figs. 3 and 4 represent three different regulatory breakpoints: the regulation limit for reuse which in the Italian legislation allows for a recovery of non-hazardous waste with the purpose of reuse (i.e., roadbed material or high-end construction material) [30] and the regulation limit for landfill disposal either as inert or non-hazardous [31] as reference wastewater analysis. The choice of using the Italian regulation as reference was done due to its stricter nature compared to those in other European countries [32]. It is noteworthy that the law limit for the reuse is higher than those fixed for landfilling disposal as inert material.

All the elements in the chemical analysis of the geopolymers come from the raw starting materials (including
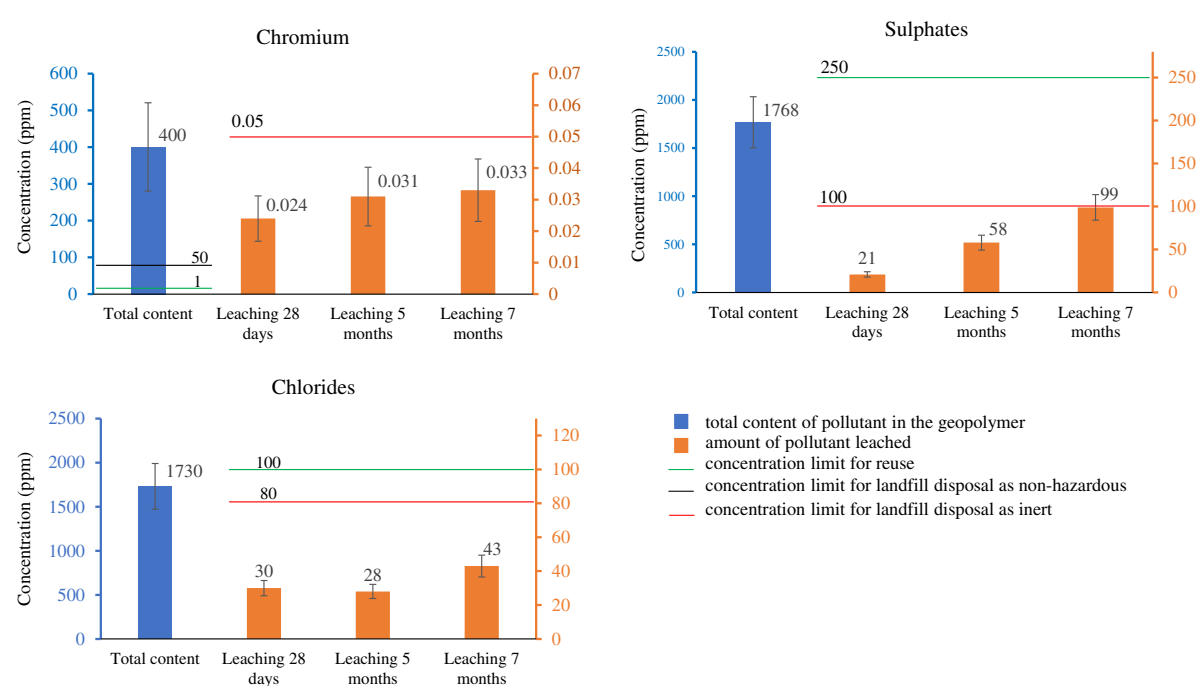

total content of pollutant in the geopolymer

amount of pollutant leached

concentration limit for reuse

_ concentration limit for landfill disposal as non-hazardous

_ concentration limit for landfill disposal as inert

Fig. 3 Main pollutants comparison after leaching tests on the
current Italian regulation. All values are reported in ppm 

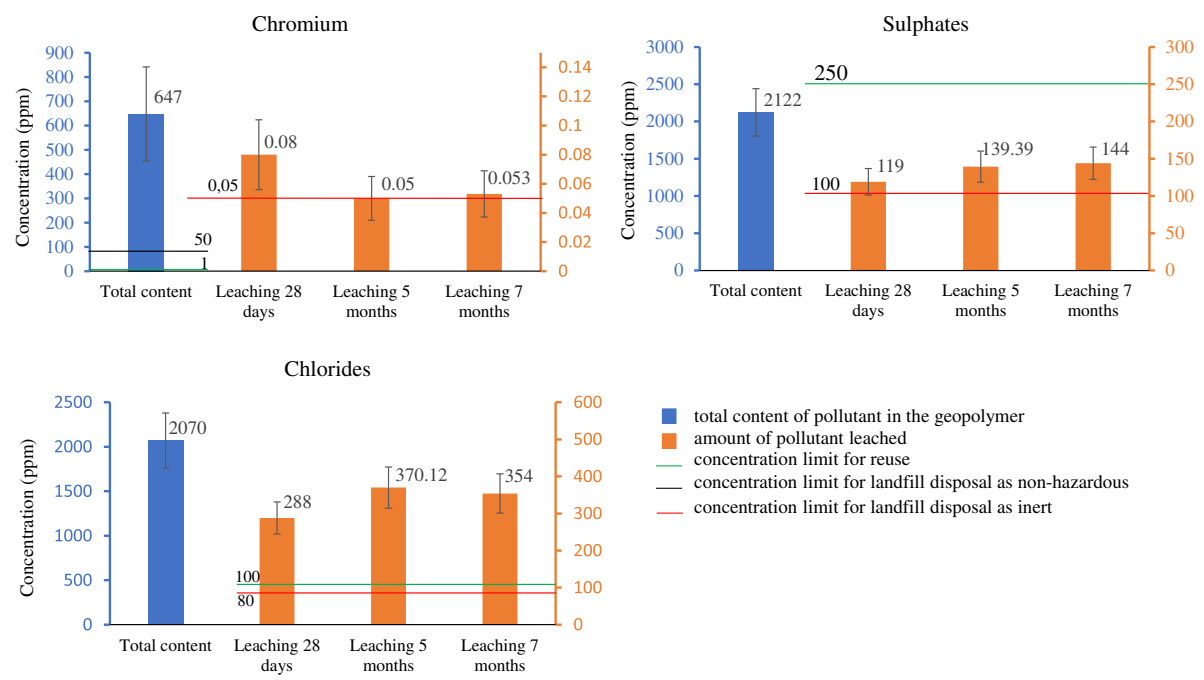

relative industrial contamination) or the tannery wastewaters. Whenever the concentration of a certain element in the chemical analysis of the geopolymer is considerably higher than in the tannery wastewater, this element has to be considered as part of the starting aluminosilicate powder, i.e., MK, or of the alkaline activating solutions.

The content of MK contaminants (As, $\mathrm{Ba}, \mathrm{Pb}, \mathrm{Fe}, \mathrm{P}$, $\mathrm{Ni}$ ), in the elementary analysis (see supplemental material Tables S2 and S3) is consistent throughout the two different geopolymer formulations. As a matter of fact, the content of iron, potassium and lead are comparable in all the geopolymers.

The amount of chromium found in the elementary analysis is consistent with the amount expected from the theoretical calculation, with a $10 \%$ error margin. This implies that during the preparation, mixing and curing process there was no loss of wastewater and the solidification process was efficiently performed.

Referring to the leaching test performed in geopolymers prepared with both tannery wastewater as received and concentrated 2:1 (MTWN, MTWC), we noticed that the release of chromium, being the most concentrated pollutant, is negligible. Since we are aware that geopolymerization can cause oxidation of some metals, we checked the oxidation state of chromium in our material via X-ray Absorption Spectroscopy [33] and we had confirmation of absence of $\mathrm{Cr}(\mathrm{VI})$.

The results of leaching tests performed on MTWN are well below all Italian regulations with the exception of fluoride (which is slightly above the limit, see supplemental materials). MTWC can be disposed as nonhazardous material but shows some values higher than those allowed for reuse or inert disposal. For instance, chlorides and sulphates leach out from the MTWC materials at values above the regulation limit for the disposal as an inert waste or for reuse, but they are well within the limit of requirement for the disposal as a non-hazardous waste which falls above the maximum values shown in the graphs (2500 $\mathrm{ppm})$.

The checking of the amount of $\mathrm{Cl}^{-}$and $\mathrm{SO}_{4}{ }^{2-}$ leached out was crucial because of their high concentration in tannery wastewater. For MTWN, the quantity released of these anions in the leaching tests is constant in time in the range of few 10 of ppm, whereas in the MTWC tests, the amount raises to hundreds of ppm.

To assess the performance of the proposed S/S technique, we calculated the percentage of pollutants retention after 7 months (Fig. 5) by comparing the amount of substance leached out (according to UNI EN 12457-22004) with the amount of substance present in the geopolymer.

The leached amount of all the ions incorporated into the geopolymer matrix is stable overtime. From these results, we can assess that in no cases, the maximum capacity of waste stabilization was reached, therefore the materials have potentially a greater efficiency than what we have studied so far. It is important to note that, even in the case of amounts of leached pollutants higher than the limits relative to reuse, the results are very promising since the procedure or raw materials have not yet been optimized nor pre-treated.

The novelty in the reticulation mechanism that causes the geopolymer to be effectively stabilized and to entrap either cations, anions and macromolecules can be hypothesized to be the in-situ formation of zeolite structures as already been evidenced by previous reports [34, 35]. The cations entrapment in the matrix can be 


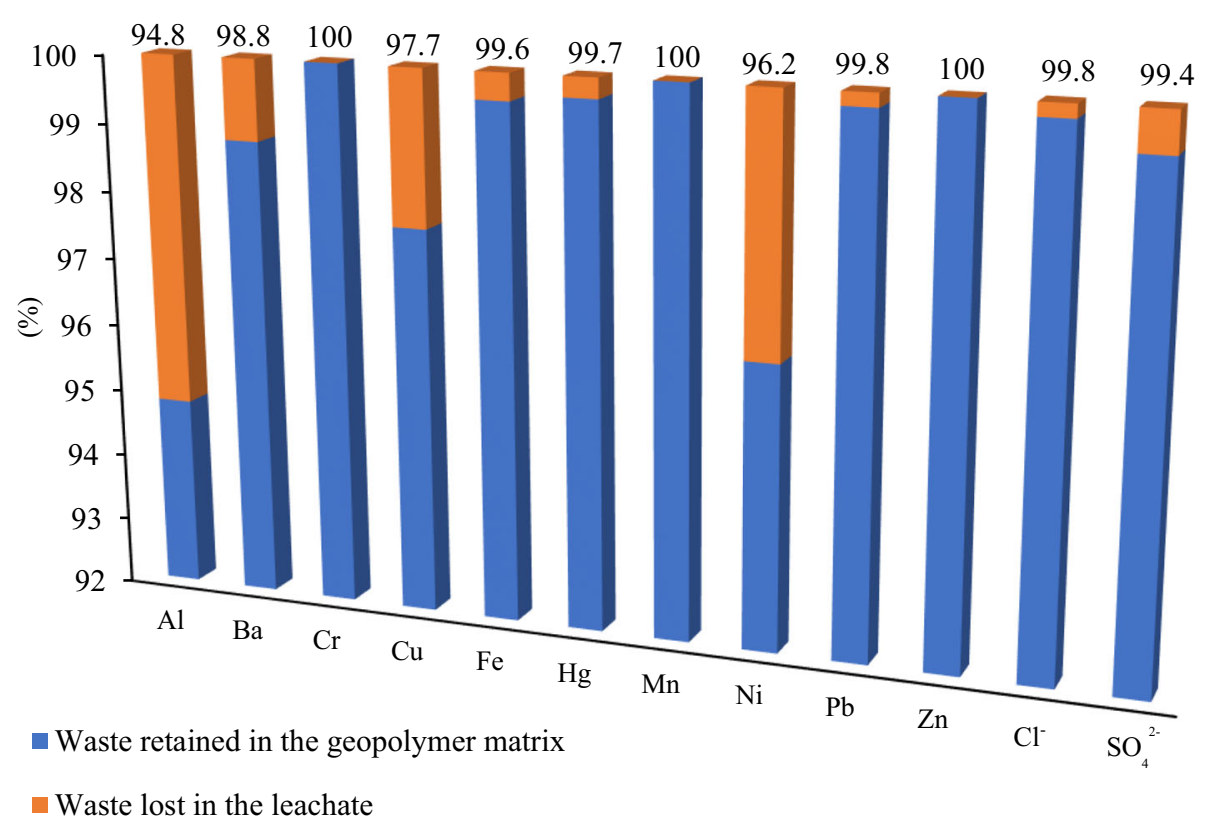

Fig. 5 Graphical representation of waste retention at 7 months after geopolymerization. Total waste retained confirmed via ICP-OES

explained with the zeolite formation, same is for anions, see for example sodalite structure, a zeolite containing $\mathrm{Cl}$ ions: characterized by chemical formula $\mathrm{Na}_{8} \mathrm{Al}_{6}$ $\mathrm{Si}_{6} \mathrm{O}_{24} \mathrm{Cl}_{2}$. Whilst surfactants macromolecules, due to their high volume, are physically entrapped in zeoliticlike cages of the 3D aluminosilicate network.

As a matter of fact, the geopolymerization route has been already used for the synthesis of nanozeolites with different crystal structures by exploring the $\mathrm{Na}-\mathrm{Al}-\mathrm{Si}-$ $\mathrm{H}_{2} \mathrm{O}$ quaternary phase space under a mild hydrothermal condition [36]. The kinetics of cations leaching from geopolymers based on different aluminosilicate precursors has been studied [37]. The leaching process has been qualitatively found to proceed via a combination of pore diffusion and boundary diffusion control mechanisms [38, 39]. In those first works [38, 39], the immobilization of the cations in the $3 \mathrm{D}$ aluminosilicate structure has been hypothesized to be a combination of physical encapsulation and chemical bonding while only recently has been proved to be specifically chemical for low cation concentrations [33].

\section{Evaluation of the wastewater treatment process performance}

As previously mentioned, to the best of our knowledge, there are no studies in the literature that use a real matrix of tanning wastewater to attempt a meaningful reduction of the mobility of pollutants using the formation of geopolymers as $\mathrm{S} / \mathrm{S}$ technique. Other works have the additional process of sludge stabilization, thus adding a layer of complexity to the process. In Table 3 some comparisons were made with other $\mathrm{S} / \mathrm{S}$ techniques reported in literature.

Two out of the three studies considered in this comparative table use dry sludge taken directly from the central wastewater treatment plant where chromium is removed from solution via precipitation. The resulting sludge is dried and tested for its leaching potential which is the value used to compare the effectiveness of stabilization after the solidification process. Our S/S method uses the native wastewater taken directly from the tanning drum at the end of the process. Such an approach removes the need for additional water usage. The performance of our method can be compared only with Montanes et al. [14] since the other works do not provide all the data needed for a proper confrontation. If we compare the quantity of chromium leached out from the geopolymer with the quantity present in the solid after $\mathrm{S} / \mathrm{S}$, we can estimate a retention potential of $96.2 \%$ (the calculation was done considering also the quantity of water added) for Montanes et al. and $99.994 \%$ for our method. Please notice that for this comparison we picked their best performing formulation, which is composed of $90 \%$ dry sludge, $10 \%$ cement and a $40 \mathrm{wt} \%$ of added water.

The synoptic scheme (Fig. 6) shows a visual representation of our method compared with the three aforementioned processes. The simplified procedure that we propose appears on the left side of the scheme where no $\mathrm{Cr}$ precipitation is operated. On the right side of the scheme, the wastewater treatments with filter pressing and no filter pressing are reported. 
Table 3 *Leaching potential $=\mathrm{Cr}$ released from the sludge without S/S treatment. ** These studies collect the sludge after the $\mathrm{Cr}$ precipitation process. ${ }^{* *}$ No quantification on the amount of water used nor on the exact amount of chromium in the sludge. ****The value is presented with more significant figures to allow a better comparison

\begin{tabular}{|c|c|c|c|c|c|c|c|}
\hline S/S approaches & $\begin{array}{l}\text { Pretreatment of } \mathrm{Cr}- \\
\text { bearing wastewater }\end{array}$ & $\begin{array}{l}\mathrm{Cr} \text { in solution* } \\
\text { (leaching potential) }\end{array}$ & Additional water & $\begin{array}{l}\mathrm{Cr} \text { in the } \\
\text { product } \\
\left(\mathrm{mg} \mathrm{kg}^{-1}\right)\end{array}$ & $\begin{array}{l}\text { Leaching } \\
\left(\mathrm{mg} \mathrm{L}^{-1}\right)\end{array}$ & $\begin{array}{l}\text { Mass } \\
\text { increase }\end{array}$ & $\begin{array}{l}\% \text { of } \mathrm{Cr} \\
\text { retained }\end{array}$ \\
\hline $\begin{array}{l}\text { Ladle furnace slag + } \\
\text { organoclay [13] }\end{array}$ & Yes** & $42 \mathrm{mg} \mathrm{kg}^{-1}$ & $\begin{array}{l}\text { Yes, no indication of } \\
\text { the amount }\end{array}$ & $* * *$ & 1.2 & $1: 3.3$ & *** \\
\hline Portland cement [14] & Yes** & $385 \mathrm{mg} \mathrm{kg}^{-1}$ & $40 \mathrm{wt} \%$ & 5080 & 194.7 & $1: 1.55$ & $96.2 \%$ \\
\hline Portland cement [15] & Yes (filtration) & $7.50 \mathrm{mg} \mathrm{L}^{-1}$ & no & 0.68 & 0 & $1: 11$ & $100 \%$ \\
\hline Metakaolin (this work) & No & $4100 \mathrm{mg} \mathrm{L}^{-1}$ & no & 400.55 & 0.024 & $1: 10$ & $99.994 \% * * * *$ \\
\hline
\end{tabular}

\section{Conclusions}

A significant number of operations within a tannery industry are wet operations consuming large amounts of liquids leading to large amounts of polluted water requiring special treatment due to the high concentration of $\mathrm{Cr}$ (III) ions and the presence of other chemical reagents that are toxic or harmful for the environment. We demonstrated that:

1) By means of alkaline activation, a complex tannery wastewater has been effectively and efficiently transformed into solid material. Also concentrated solutions are adequate for the proposed inertization process, thus indicating that the starting content of cations, anions and surfactants can be very variable without affecting the efficiency of our consolidation/chemical inertization process.
2) The consolidated material efficiently immobilizes heavy metals, anions and macromolecules (surfactants) for safe disposal. As far as the $\mathrm{Cr}$ leaching potential is concerned, we measured a retention of $99.994 \%$ which is among the best performance reported to date.

3) The absence of wastewater pre-treatment in our zero-water technology led to a single step S/S process of the as-produced waste liquor without the necessity to add clean water. This last step goes in the direction of preserving fresh water as fostered by the European Commission for the industry of the future, whilst the majority of other similar studies demand additional water due to the use of dry sludge instead of wastewater.

4) The inertization process can be modulated around the product we want to obtain either for reuse or safe disposal. In any case, the cost balance has to consider

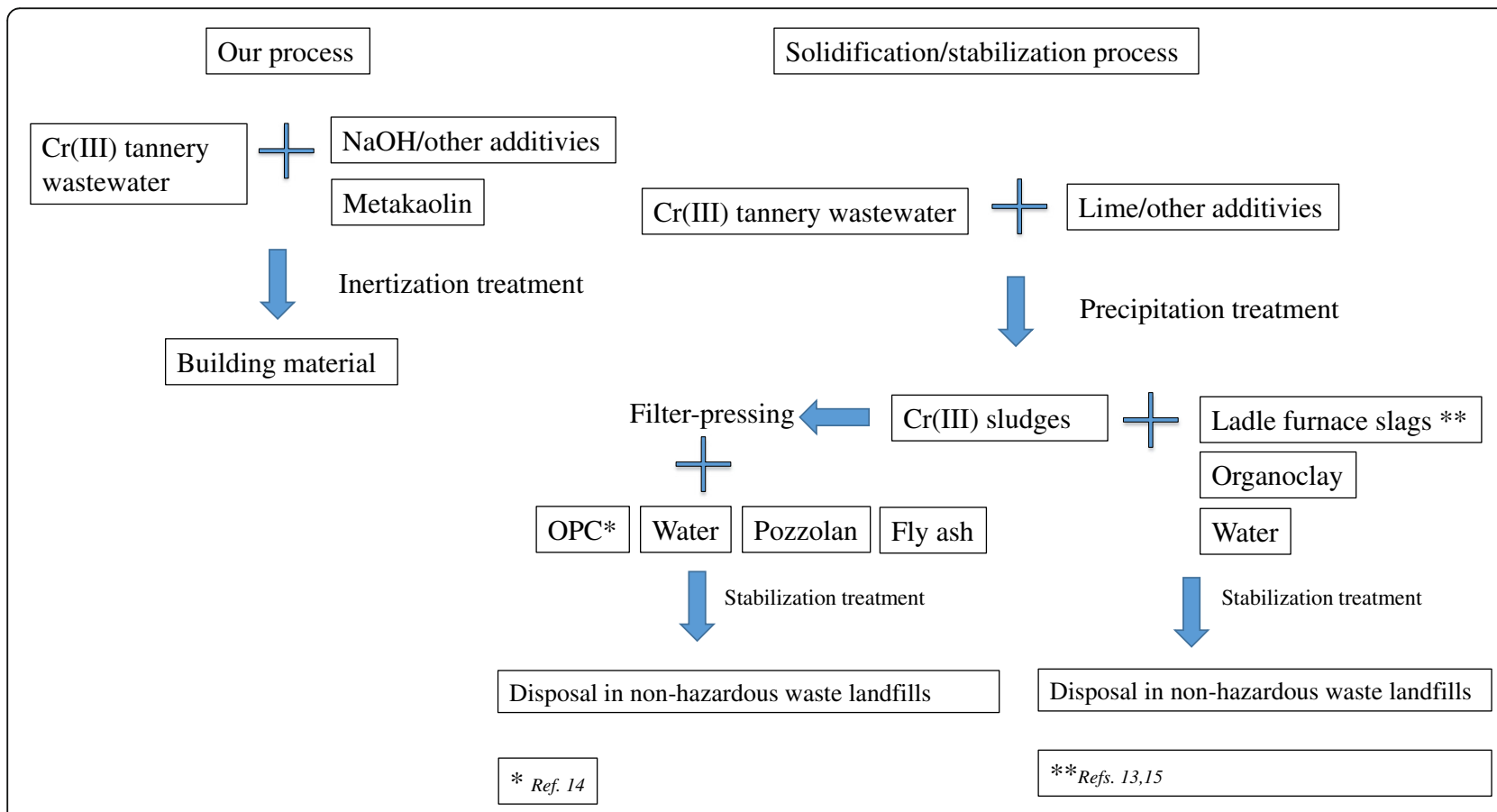

Fig. 6 Visual representation of the method proposed compared to other $S / S$ approach for tannery wastewater 
the savings made on infrastructures since all it is needed for the geopolymer preparation is a cement mixer. The resulting experience reinforces the concept of "zero waste" and "no water consumption" for a sector which is globally considered one of the most polluting [6]. A new concept of waste is thus identified, which from a problem becomes a resource for the community.

5) The leaching tests performed according to current regulation attested that after 5 months of aging the materials have increased their capabilities to retain cations, anions and macromolecules of surfactants. These results are considered of extreme importance in attesting the durability of the final consolidated product that can be used as high-end products for the building industry. As an example, exploiting the intrinsic fire resistance properties of these materials, they can be suitable as refractory bricks and fireplace elements [40]. For this purpose, it is important to note that only the geopolymer made with the wastewater used as received meets the requirement for reuse as noted in Figs. 3 and 4 (also in Tables S2 and $\mathrm{S} 3$ in the supplementary materials).

In order to enhance the performance of this S/S strategy, we need to reformulate the paste composition, MK/ $\mathrm{NaOH} / \mathrm{Nasilicate} /$ wastewater ratio having in mind the final application of the solidified product. Other studies are in progress to determine the microstructure of the geopolymer which are going to be completed in the near future along with the optimization of the matrixes.

\section{Supplementary Information}

The online version contains supplementary material available at https://doi. org/10.1186/s42834-021-00106-7.

\section{Additional file 1.}

\section{Acknowledgements}

Authors express their gratitude to the suppliers of raw materials, i.e. Bal-Co S.p.A., Sassuolo, Modena, Italy, for the MK and Ingessil S.r.L., Montorio, Verona, Italy, for the sodium silicate solution, JH Conceria del Chienti spa Tolentino, Italy, for the liquid waste.

\begin{abstract}
Authors' contributions
Giacomo Boldrini: Investigation, Data curation, Visualization and Writing original draft; review \& editing; Caterina Sgarlata: Investigation, Methodology; Isabella Lancellotti: Conceptualization, Data curation, Writing - review \& editing; Luisa Barbieri: Formal analysis; Writing - review Marco Giorgetti: Investigation, Validation; Michela Ciabocco: Investigation; Silvia Zamponi: Resources acquisition; Mario Berrettoni: Supervision, Data curation, Writing review \& editing; Cristina Leonelli: Supervision, Data curation, Writing review \& editing; All authors have read and approved the final manuscript.
\end{abstract}

\section{Funding}

No funding was received.

\section{Availability of data and materials}

All data generated or analyzed during this study are included in this published article [and its supplementary information files].

\section{Declarations}

\section{Competing interests}

The authors declare that they have no competing interests" in this section.

\section{Author details}

'University of Camerino, School of Science and Technology, 62032 Camerino, Italy. 2Department of Engineering "Enzo Ferrari", University of Modena and Reggio Emilia, 41125 Modena, Italy. ${ }^{3}$ Department of Industrial Chemistry "Toso Montari", University of Bologna, 40136 Bologna, Italy. ${ }^{4}$ Analisi Control S.r.L, 62014 Corridonia, Italy.

Received: 4 December 2020 Accepted: 8 August 2021

Published online: 19 October 2021

\section{References}

1. UNIDO. Future Trends in the World Leather and Leather Products Industry and Trade. Vienna: United Nations Industrial Development Organization; 2010

2. FAO. World statistical compendium for raw hides and skins, leather and leather footwear 1999-2015. Rome: Food and Agriculture Organization; 2016.

3. UNIC. The Sustainable Goals of the Italian Leather. Milan: Italian Tanners' Association; 2019. https://unic.it/storage/Rapporto\%20sostenibilit\%c3\%a0\%2 02019/Report_UNIC_2019_ENG.pdf.

4. Seyoum L, Fassil A, Gunnel D. Characterization of tannery wastewater and assessment of downstream pollution profiles along Modjo River in Ethiopia. Ethiop J Biol Sci 2003;2:157-68.

5. Rivela B, Moreira MT, Bornhardt C, Mendez R, Feijoo G. Life cycle assessment as a tool for the environmental improvement of the tannery industry in developing countries. Environ Sci Technol 2004;38:1901-9.

6. UNIDO. Introduction to treatment of tannery effluents. Vienna: United Nations Industrial Development Organization; 2011.

7. Kolomaznik K, Adamek M, Andel I, Uhlirova M. Leather waste - potential threat to human health, and a new technology of its treatment. J Hazard Mater 2008;160:514-20.

8. Tunay O, Kabdasli I, Orhon D, Ates E. Characterization and pollution profile of leather tanning industry in Turkey. Water Sci Technol 1995;32:1-9.

9. Dixit S, Yadav A, Dwivedi PD, Das M. Toxic hazards of leather industry and technologies to combat threat: a review. J Clean Prod 2015;87:39-49.

10. Panizza M, Cerisola G. Electrochemical oxidation as a final treatment of synthetic tannery wastewater. Environ Sci Technol. 2004;38:5470-5.

11. Covington AD. Tanning chemistry: the science of leather. 1st ed. Cambridge: Royal Society of Chemistry; 2011.

12. Jin MT, Lian F, Xia RQ, Wang ZH. Formulation and durability of a geopolymer based on metakaolin/tannery sludge. Waste Manage 2018;79: 717-28.

13. Pantazopoulou E, Zouboulis A. Chemical toxicity and ecotoxicity evaluation of tannery sludge stabilized with ladle furnace slag. J Environ Manage 2018; 216:257-62.

14. Montanes MT, Sanchez-Tovar R, Roux MS. The effectiveness of the stabilization/solidification process on the leachability and toxicity of the tannery sludge chromium. J Environ Manage 2014;143:71-9.

15. Haque MA, Chowdhury RA, Chowdhury WA, Baralaskar AH, Bhowmik S, Islam S. Immobilization possibility of tannery wastewater contaminants in the tiles fixing mortars for eco-friendly land disposal. J Environ Manage 2019;242:298-308

16. Luukkonen T, Heponiemi A, Runtti H, Pesonen J, Yliniemi J, Lassi U. Application of alkali-activated materials for water and wastewater treatment: a review. Rev Environ Sci Biol 2019;18:271-97.

17. Ponzoni C, Lancellotti I, Barbieri L, Spinella A, Saladino ML, Martino DC, et al. Chromium liquid waste inertization in an inorganic alkali activated matrix: leaching and NMR multinuclear approach. J Hazard Mater 2015;286:474-83.

18. Leonelli C, Kamseu E, Lancellotti I, Barbieri L. Geopolymerization as coldconsolidation techniques for hazardous and non-hazardous wastes. Key Eng Mater 2017;751:527-31.

19. Barbieri L, Kamseu E, Lancellotti I, Leonelli C, Ponzoni C. Procedure for inertization of liquid waste. Rome: Italian Patent and Trademark Office; 2014. [in Italian] https://worldwide.espacenet.com/patent/search/family/04658413 6/publication/ITRE20120028A1?q=ITRE20120028. 
20. Pacheco-Torgal JF, Labrincha A, Leonelli C, Palomo A, Chindaprasirt P. Handbook of alkali-activated cements, mortars and concretes. Cambridge: Woodhead Publishing; 2015.

21. Chen JY, Wang YH, Wang HQ, Zhou S, Wu HD, Lei XR. Detoxification/ immobilization of hexavalent chromium using metakaolin-based geopolymer coupled with ferrous chloride. J Environ Chem Eng 2016;4: 2084-9.

22. Dhal B, Pandey BD. Mechanism elucidation and adsorbent characterization for removal of Cr (VI) by native fungal adsorbent. Sustain Environ Res 2018; 28:289-97.

23. Kan CC, Ibe AH, Rivera KKP, Arazo RO, de Luna MDG. Hexavalent chromium removal from aqueous solution by adsorbents synthesized from groundwater treatment residuals. Sustain Environ Res 2017;27:163-71.

24. Quiton KG, Doma B, Futalan CM, Wan MW. Removal of chromium (VI) and zinc (II) from aqueous solution using kaolin-supported bacterial biofilms of Gram-negative E. coli and Gram-positive Staphylococcus epidermidis. Sustain Environ Res 2018;28:206-13.

25. Thanikaivelan P, Rao JR, Nair BU, Ramasami T. Zero discharge tanning: a shift from chemical to biocatalytic leather processing. Environ Sci Technol 2002; 36:4187-94.

26. Elsheikh MAS. Tannery wastewater pre-treatment. Water Sci Technol 2009; 60:433-40.

27. Metcalfe TL, Dillon PJ, Metcalfe CD. Detecting the transport of toxic pesticides from golf courses into watersheds in the Precambrian Shield region of Ontario, Canada. Environ Toxicol Chem 2008;27:811-8.

28. Lancellotti I, Ponzoni C, Barbieri L, Leonelli C. Alkali activation processes for incinerator residues management. Waste Manage 2013;33:1740-9.

29. Duxson P, Mallicoat SW, Lukey GC, Kriven WM, van Deventer JSJ. The effect of alkali and Si/Al ratio on the development of mechanical properties of metakaolin-based geopolymers. Colloid Surface A 2007;292:8-20.

30. Ministry of the Environment. Identification of non-hazardous waste subjected to simplified recovery procedures. Gazzetta Ufficiale 1998;88:1-77 [in Italian]. www.gazzettaufficiale.it/eli/gu/1998/04/16/88/so/72/sg/pdf.

31. Ministry of the Environment. Definition of the admissibility criteria for landfill waste. Gazzetta Ufficiale 2015;211:5-7 [in Italian]. http://www.ga zzettaufficiale.it/eli/gu/2015/09/11/211/sg/pdf.

32. Council of the European Union. Establishing criteria and procedures for the acceptance of waste at landfills pursuant to Article 16 and Annex II to Directive 1993/31/EC. Off J Eur Commun 2003;11:27-49. https://eur-lex. europa.eu/legal-content/EN/TXT/PDF/?uri=CELEX:32003D0033\&amp,from= EN.

33. Giorgetti M, Berrettoni M, Aquilanti G, Boldrini G, Lancellotti I, Leonelli C. The coordination core and charge of chromium in Metakaolin-geopolymers as revealed by X-Ray absorption spectroscopy. Mater Lett. 2020;270:127741.

34. Fernandez-Jimenez A, Macphee DE, Lachowski EE, Palomo A. Immobilization of cesium in alkaline activated fly ash matrix. J Nucl Mater 2005;346:185-93.

35. Vespa M, Dahn R, Wieland E. Competition behavior of metal uptake in cementitious systems: an XRD and EXAFS investigation of Nd- and Znloaded $11 \AA$ tobermorite. Phys Chem Earth 2014;70-1:32-8.

36. Chen SJ, Zhang WW, Sorge LP, Seo DK. Exploratory synthesis of low-silica nanozeolites through geopolymer chemistry. Cryst Growth Des 2019;19: 1167-71.

37. VanJaarsveld JGS, VanDeventer JSJ, Lorenzen L. The potential use of geopolymeric materials to immobilise toxic metals: part 1. Theory and applications. Miner Eng 1997;10:659-69.

38. Van Jaarsveld JGS, Van Deventer JSJ, Lorenzen L. Factors affecting the immobilization of metals in geopolymerized flyash. Metall Mater Trans B 1998;29:283-91.

39. Van Jaarsveld JGS, Van Deventer JSJ, Schwartzman A. The potential use of geopolymeric materials to immobilise toxic metals: part II. Material and leaching characteristics. Miner Eng 1999;12:75-91.

40. Luukkonen T, Abdollahnejad Z, Yliniemi J, Mastali M, Kinnunen P, Illikainen M. Alkali-activated soapstone waste - mechanical properties, durability, and economic prospects. Sustain Mater Technol 2019;22:e00118.

\section{Publisher's Note}

Springer Nature remains neutral with regard to jurisdictional claims in published maps and institutional affiliations.

\section{Ready to submit your research? Choose BMC and benefit from}

- fast, convenient online submission

- thorough peer review by experienced researchers in your field

- rapid publication on acceptance

- support for research data, including large and complex data types

- gold Open Access which fosters wider collaboration and increased citations

- maximum visibility for your research: over $100 \mathrm{M}$ website views per year

At $\mathrm{BMC}$, research is always in progress.

Learn more biomedcentral.com/submissions 